\title{
UM REGIME AUTOCONTIDO? APONTAMENTOS SOBRE O DIREITO APLICÁVEL AOS CONTENCIOSOS NO ÂMBITO DA OMC
}

\section{A SELF-CONTAINED REGIME? NOTES ON THE LAW APPLICABLE TO THE CONTENTIOUS CASES WITHIN THE WTO}

\begin{abstract}
ARNO DAL RI JÚNIOR Doutor em Direito Internacional Econômico pela Universidade Luigi Bocconi de Milão, com pós-doutorado pela Universidade de Paris 1 (Panthéon-Sorbonne). Mestre em Direito e Política da União Europeia pela Universidade de Pádua. Professor de Teoria e História do Direito Internacional no Centro de Ciências Jurídicas da Universidade Federal de Santa Catarina (UFSC). Coordenador do Grupo de Pesquisa em Direito Internacional - CNPq/UFSC. arnodalri@gmail.com

MARIANA Clara DE ANDRADE Mestranda em Direito e Relações Internacionais pela Universidade Federal de Santa Catarina e Bacharel em Direito pela mesma instituição. Membro do Grupo de Pesquisa em Direito Internacional lus Gentium (UFSC/CPNq).
\end{abstract}

mariana.clara@live.com

\section{RESUMO}

No cenário da intensificação das relações interestatais, com o aumento da criação de normas e tribunais internacionais, emerge a discussão acerca dos chamados regimes autocontidos, particularmente especializados, e a sua relação com as demais fontes de direito internacional geral. Esse artigo objetiva analisar a posição da Organização Mundial do Comércio (OMC) nesse contexto, questionando se referida organização pode ser enquadrada como um regime autocontido. Para tanto, inicialmente serão analisados os conceitos doutrinários acerca dos regimes autocontidos, para que se observe em que medida, no contexto da doutrina do direito internacional, o direito da OMC pode assim ser definido. Em seguida, abordar-se-á as disposições normativas relevantes presentes nos acordos da OMC. Finalmente, serão abordados alguns contenciosos que poderão auxiliar na resposta à questão aqui proposta. Verifica-se, após essa análise, que existe uma interação das normas da OMC com as normas de direito internacional público e, a partir disso, concluise que a organização não é um sistema completamente isolado e autônomo.

Palavras-chave: Organização Mundial do Comércio; fontes de Direito Internacional; fragmentação; regimes autocontidos.

\begin{abstract}
In a scenario of intensification of interstate relations, along with the increasing number of international rules and tribunals, the discussion over the so-called self-contained regimes, uniquely specialized, and their relation with other norms of general international law grows along. The scope of this paper is to analyze the position of the World Trade Organization (WTO) within this context, and proposes the question of whether said institution can be considered to be a selfcontained regime. To that end, this work initially brings the scholar concepts of the idea of a selfcontained regime, so as to verify if it is possible, according to these doctrinal studies, to consider WTO law as such. After this first section, the relevant legal provisions of the WTO treaties will be brought about. Finally, some contentious cases brought upon the dispute settlement system of the institution will be studied, in order to aid investigating proposed problem. Thus, this work verifies the existence of an interaction of WTO law with general public international law and, therefore, concludes that the organization is not a completely isolated and autonomous regime.
\end{abstract}

Keywords: World Trade Organization; sources of international law; fragmentation; self-contained regimes. 


\section{SUMÁRIO}

INTRODUÇAO; 1 APONTAMENTOS CONCEITUAIS: A OMC E A NOÇÃO DE REGIME AUTOCONTIDO; 2 APONTAMENTOS NORMATIVOS: AS DISPOSIÇÕES DO ESC SOBRE O DIREITO APLICÁVEL À OMC; 3 APONTAMENTOS JURISPRUDENCIAIS: INDÍCIOS PRAGMÁTICOS; CONCLUSÃO; REFERÊNCIAS.

\section{INTRODUÇÃO}

$\mathrm{Na}$ era do debate sobre a fragmentação do direito internacional, com a proliferação de fontes e tribunais internacionais, um tema que suscita percuciente discussão envolve os chamados regimes autocontidos (termo derivado do inglês self-contained regimes) ${ }^{1}$. Tais regimes têm por característica marcante sua especialização em relação às normas de direito internacional geral, e um sistema próprio de responsabilização de seus sujeitos. É o fato de eles regerem-se de uma maneira própria que, em teoria, os afastaria do direito internacional público geral.

Dois subsistemas de direito internacional frequentemente mencionados como exemplos de regimes autocontidos são a União Europeia (UE) e a Organização Mundial do Comércio (OMC) ${ }^{2}$. Esta última, foco deste trabalho, conta com um complexo aparato normativo e um reconhecido e efetivo sistema de resolução de litígios, o Mecanismo de Solução de Controvérsias (MSC). A consideração de que a OMC seria um regime autocontido é ainda reforçada pelo fato de que seu MSC se cinge essencialmente às obrigações acordadas dentro de seu próprio âmbito.

$\mathrm{Na}$ mesma linha das crescentes discussões acerca da fragmentação do direito internacional e da proliferação de normas e jurisdições internacionais, bem como diante do reconhecimento da influência das relações comerciais em outros âmbitos do direito como o meio ambiente e os direitos humanos, igualmente ganha força o debate sobre a relação das normas do dito regime autocontido da Organização Mundial do Comércio e outras fontes de direito internacional público, cujas obrigações podem inclusive ser colidentes.

Nesse contexto, o objetivo do presente trabalho é analisar a interação das normas de direito internacional geral com as normas do sistema jurídico da OMC. A questão, no âmbito do

\footnotetext{
${ }^{1}$ Sobre o tema, cf. particularmente os seguintes trabalhos constantes das referências bibliográficas deste artigo: LINDROOS; MEHLING (2006), PULKOSWKI; SIMMA (2006), KOSKENNIEMI (2004). O último trabalho, em particular, é parte de uma série de estudos acerca do fenômeno da fragmentação internacional, dirigidos por Martti Koskenniemi dentro da Comissão de Direito Internacional da ONU.

${ }^{2}$ CRAWFORD, James. Chance, Order, Change: The Course of International Law. The Hague: Brill, 2013, para. 388 e 389.
} 
UM REGIME AUTOCONTIDO? APONTAMENTOS SOBRE O DIREITO APLICÁVEL AOS CONTENCIOSOS NO ÂMBITO DA OMC

ARno Dal RI JÚNIOR, MARIANA CLARA DE ANDRADE

MSC/OMC, emerge clara quando se põe desta forma: ainda que as normas de comércio internacional façam parte do direito internacional como um todo, até que ponto o MSC pode considerar e executar as obrigações que os seus Estados-membros concluem fora do âmbito da $\mathrm{OMC} ?^{3}$

Para tanto, este artigo está dividido em três partes: inicialmente, explanar-se-á brevemente a estrutura da OMC e a organização de seus textos, para então analisar-se o conceito de regime autocontido e a sua relação com a organização objeto deste estudo. Em seguida, buscar-se-á em alguns dispositivos dos acordos da OMC elementos normativos para o exame da questão. Finalmente, serão examinados trechos de decisões relevantes do Mecanismo de Solução de Controvérsias da OMC (MSC/OMC) que possam igualmente servir para elucidar a indagação aqui postulada.

Ainda que o intuito deste trabalho não seja oferecer uma resposta definitiva a tal questão, busca-se demonstrar, principalmente a partir dos dispositivos normativos da organização e de considerações doutrinárias sobre o tema, que as obrigações concluídas dentro do âmbito da OMC devem interagir com as demais obrigações de direito internacional a que os Estados se comprometem.

\section{APONTAMENTOS CONCEITUAIS: A OMC E A NOÇÃO DE REGIME AUTOCONTIDO}

Para uma melhor compreensão do debate, é necessário explanar brevemente alguns aspectos da estrutura da Organização Mundial do Comércio, para, em seguida, tratar-se do conceito de regime autocontido e sua relação com a mencionada organização.

A OMC, embora estabelecida em 1995, encontra origens em momento anterior: seus princípios basilares foram acordados pelo sistema instituído pelo Acordo Geral sobre Tarifas Aduaneiras e Comércio (GATT - General Agreement on Tariffs and Trade), em 1948, e foram gradativamente desenvolvidos até a instituição da organização internacional. Esse acordo foi articulado principalmente pelos Estados Unidos, e tinha por objetivo a redução de tarifas ${ }^{4}$.

\footnotetext{
${ }^{3} \mathrm{Em}$ contraposição à questão que o MSC da OMC deve efetivamente responder, conforme Koskenniemi e Leino: "Has WTO law been violated?" (KOSKENNIEMI, Martti; LEINO, Päivi. Fragmentation of International Law? Postmodern Anxieties. Leiden Journal Of International Law, Leiden, v. 15, n. 3, p.553-579, nov. 2002, p. 571).

${ }^{4}$ STOLL, Peter-tobias; SCHORKOPF, Frank. World Economic Order, World Trade Law. Leiden: Martinus Nijhoff, 2006. (Max Planck Commentaries on World Trade Law), p. 12.
} 
UM REGIME AUTOCONTIDO? APONTAMENTOS SOBRE O DIREITO APLICÁVEL AOS CONTENCIOSOS NO ÂMBITO DA OMC

ARno DAL Ri JÚNIOR, MARIANA CLARa de ANDRAde

A criação do sistema GATT inaugurou ainda uma sucessão de rodadas de negociação ${ }^{5}$ entre diversos países, as quais buscavam precisamente delimitar as novas perspectivas referentes ao movimento de liberalização do comércio internacional, com a conclusão de novos acordos multilaterais. Os novos acordos concluídos no bojo dessas negociações, contudo, eram obrigações à parte do GATT' ${ }^{6}$.

O apogeu das rodadas de negociação se deu com a Rodada do Uruguai, em que se estabeleceu o GATT/94, em substituição ao GATT/47. O texto do GATT/94 adicionou alguns instrumentos legais ao texto, mas não modificou substancialmente suas provisões, e implementou também uma série de decisões suplementares tomadas pelas suas partes contratantes ${ }^{7}$.

Uma particular inovação da Rodada do Uruguai foi ainda que todos os acordos concluídos nas negociações até aquele momento foram unificados em um "pacote", que poderia ser aceito ou recusado apenas em sua inteireza ${ }^{8}$, e não mais individualmente como anteriormente. Finalmente, excedendo-se as expectativas da rodada (que já não eram modestas), esta culminou com a instituição da Organização Mundial do Comércio. Nas palavras de Dal Ri Júnior, "os movimentos ocorridos no âmbito do GATT durante a evolução do ciclo do Uruguai trouxeram sensíveis mudanças ao quadro jurídico do comércio internacional"9.

A OMC valeu-se do pacote de acordos que haviam se unificado ao sistema GATT, institucionalizando-o definitivamente. De fato, uma das grandes diferenças do GATT/47 e o sistema da OMC, conforme observam Hoekman e Mavroidis, é justamente o aspecto estrutural que a organização recebeu, uma vez que fazer parte da OMC significa a aceitação de todas as provisões de seus Acordos Multilaterais, enquanto no sistema GATT cada membro decidia de quais provisões e acordos abrangidos participaria ${ }^{10}$.

\footnotetext{
5 Tais foram as rodadas: Genebra (1947), Annecy (1949), Torquay (1951), Dillon Round (1960-1961), Kennedy Round (1964-1967), Tokyo Round (1973-1979) e Uruguay Round (1986-1994).

${ }^{6}$ STOLL E SCHORKOPF, op. cit., p. 13.

7 IRWIN, Douglas A.; C.MAVROIDIS, Petros; SYKES, Alan O.. The Genesis of the GATT. New York: Cambridge University Press, 2008, p. 103 e 119.

${ }^{8}$ STOLL; SCHORKOPF, op. cit., p. 13.

9 DAL RI JÚNIOR, Arno. História do Direito Internacional: Comércio e Moeda, Cidadania e Nacionalidade. Florianópolis: Fundação Boiteux, 2004, p. 152-153. Para uma descrição mais detalhada sobre os percalços das Rodadas de Negociação até o Uruguay Round, cf. DAL RI JÚNIOR, idem, pp.135-161

10 HOEKMAN, Bernard M.; MAVROIDIS, Petros C.. The World Trade Organization: law, economics and politics. New York: Routledge, 2007. (Global Institutions Series), p. 29.
} 
UM REGIME AUTOCONTIDO? APONTAMENTOS SOBRE O DIREITO APLICÁVEL AOS CONTENCIOSOS NO ÂMBITO DA OMC

ARNo DAL RI JÚNIOR, MARIANA CLARA DE ANDRADE

O Acordo Constitutivo da OMC traz consigo uma lista de quatro anexos, os quais configuram as obrigações e direitos dos seus membros ${ }^{11}$. 0 Anexo 1 enumera os Acordos de Comércio Multilaterais (relativos à comercialização de bens, de serviços e relativos à propriedade intelectual), enquanto o Anexo 4 traz os Acordos de Comércio Plurilaterais ${ }^{12}$.

O Anexo 2 traz o Entendimento Relativo às Normas e Procedimentos Sobre Solução de Controvérsias (o ESC), que dispõe questões procedimentais relativas ao mecanismo de solução de controvérsias do sistema (MSC), formado por painéis ad hoc e um permanente Órgão de Apelação (OAp). Tal mecanismo é regido pelo Órgão de Solução de Controvérsias (OSC), o qual tem o poder de conferir juridicidade às decisões do MSC.

Finalmente, o Anexo 3 consolida o Mecanismo de Exame de Políticas Comerciais, que estabelece as normas procedimentais para a notificação e a supervisão das políticas e normas comerciais de cada um dos membros da Organização ${ }^{13}$.

Considerando ser a OMC um sistema composto de normas detalhadas e específicas, dotado de um aparelho de resolução de litígios próprio, bem como de remédios para a violação destas normas, daí advém o entendimento discutido pela doutrina de que a organização configuraria um sistema autocontido ${ }^{14}$. Tal lógica é corroborada pela pouca interação do direito criado no bojo da OMC com as demais normas de direito internacional geral, particularmente dentro do seu sistema de resolução de litígios.

James Crawford assim define um regime autocontido ${ }^{15}$ :

\footnotetext{
${ }^{11}$ HOEKMAN; MAVROIDIS, op. cit., p. 20

${ }^{12}$ Acordos multilaterais é o termo utilizado em contraposição a acordos plurilaterais, também no âmbito da OMC, cuja aceitação pelos membros é facultativa. Cf. Artigo II.3 do Acordo Constitutivo da OMC.

${ }^{13}$ BOSSCHE, Peter van Den. The Law and Policy of the World Trade Organization: Text, Cases and Materials. New York: Cambridge University Press, 2005, pp. 94 e ss.

${ }^{14}$ Pauwelyn assim esboça a questão: "Some authors have argued in this respect that WTO law is a 'selfcontained regime'in the sense of 'a certain category of subsystems, namely those embracing, in principle, a full (exhaustive and definite) set of secondary rules . . . Which is intended to exclude more or less totally the application of the general legal consequences of wrongful acts'. James Crawford, for example, submits that the DSU is, in terms of state responsibility, an example where it is 'clear from the language of a treaty or other text that only the consequences specified flow'. Kuijper also expressed the view that '[t]he intention to move further towards a self-contained system certainly underlies the WTO Agreement and its Dispute Settlement Understanding, but it remains to be seen how the WTO Members will make it function'. Other authors, in contrast, argue that general international law remedies are still relevant also in WTO dispute settlement" (PAUWELYN, Joost. Conflict of Norms in Public International Law: How WTO Law Relates to other Rules of International Law. New York: Cambridge University Press, 2003, p. 39, notas de rodapé suprimidas).

${ }^{15}$ A origem do termo, conforme explicam Simma e Pulkoswski, remonta ao caso S.S Wimbledon, levado à Corte Permanente de Justiça Internacional, em que o tribunal analisou provisõe do Tratado de Versailles vis-à-vis provisões alemãs sobre o Canal Kiel. Recentemente, lembram ainda os autores, a Corte Internacional de Justiça utilizou-se desse conceito no caso Tehran Hostages, ao examinar as normas
} 
UM REGIME AUTOCONTIDO? APONTAMENTOS SOBRE O DIREITO APLICÁVEL AOS CONTENCIOSOS NO ÂMBITO DA OMC

ARNo DAL RI JÚNIOR, MARIANA CLARA DE ANDRADE

em um sentido amplo, um regime autocontido é um pouco mais do que um formato forte de lex specialis, pelo qual uma 'série de tratados geográfica ou funcionalmente limitada' pretende derrogar as normas secundárias de direito internacional que sustentam o sistema como um todo. Mais estritamente, contudo, tais regimes podem representar um aparato de subsistemas que tratam de um determinado problema de direito internacional de maneira distinta da qual tal problema poderia ser normalmente tratado, (traduzido) ${ }^{16}$.

O autor indica, ainda, alguns elementos que levam ao entendimento de que o sistema da OMC poderia ser considerado como um regime autocontido, particularmente o seu detalhado sistema normativo e o seu órgão jurisdicional compulsório ${ }^{17}$.

$\mathrm{Na}$ mesma linha, Koskenniemi, no relatório do grupo de estudos sobre Fragmentação do Direito Internacional conduzido pela Comissão de Direito Internacional (CDI), define um regime autocontido como um sistema que perpassa um mero agregado de normas substanciais, no qual normas primárias especiais (direitos, deveres e poderes) entrelaçam-se com normas secundárias especiais (a criação e mudança dessas normas primárias, a resolução dos litígios e as reações a atos antijurídicos) ${ }^{18}$.

A dificuldade em se compreender a efetiva interação do direito da OMC com o direito externo à organização advém em parte, conforme observado por Pauwelyn, do fato de que muitos dos arquitetos do sistema não consideraram o próprio direito internacional público geral ao criá-lo ${ }^{19}$. Lindroos e Mehling lembram ainda o aspecto político da resistência dos operadores do sistema multilateral do comércio em aceitar a integração da OMC ao corpus do direito internacional ${ }^{20}$.

Ademais, a especialização das normas do direito da OMC, que detalhadamente regem o sistema multilateral de comércio internacional, muitas vezes é subsídio para a alegação de que o

específicas das relações diplomáticas em detrimento das disposições gerais de responsabilidade de Estados (PULKOWSKI, Dirk; SIMMA, Bruno. Of Planets and the Universe: Self-contained Regimes in International Law. The European Journal Of International Law, Oxford, v. 17, n. 3, p.483-529, jun. 2006, p. 491).

${ }^{16}$ Traduzido do original: "Thus, in a broad sense, a self-contained regime is little more than a strong form of lex specialis, by which a "geographically or functionally limited treaty series" attempts to contract out of the secondary rules of international law that underpin the system as a whole. More narrowly, however, such regimes may represent comprehensive sub-systems that cover a particular international law problem in a different manner from how it might be otherwise dealt with" (CRAWFORD, op. cit., para. 387).

${ }_{17}$ CRAWFORD, op. cit., para. 388.

18 KOSKENNIEMI, Martti. Outline of the Chairman of the ILC Study Group on Fragmentation of International law: The function and scope of the lex specialis rule and the question of 'self-contained regimes'. 2004, p. 8.

19 PAUWELYN, op. cit., p. 55

${ }^{20}$ LINDROOS, Anja; MEHLING, Michael. Dispelling the Chimera of 'Self-Contained Regimes' International Law and the WTO. The European Journal Of International Law, Oxford, v. 16, n. 5, p.857-877, ago. 2006, p. 873 
UM REGIME AUTOCONTIDO? APONTAMENTOS SOBRE O DIREITO APLICÁVEL AOS CONTENCIOSOS NO ÂMBITO DA OMC

ARNo DAL RI JÚNIOR, MARIANA CLARA DE ANDRADE

critério interpretativo da lex specialis privilegia o aparato normativo da instituição em detrimento do direito internacional geral.

Deve-se esclarecer, contudo, que as definições do conceito de regime autocontido supracitadas não excluem a interação desses regimes com o direito internacional geral. Com efeito, Simma e Pulkowski esclarecem que a noção de regime autocontido como um sistema plenamente isolado e autônomo é errônea ${ }^{21}$. Treves considera que contribui para esse equívoco a especialização de campos com normas e estruturas específicas, e seus operadores que, ao focarem naquela área, desfamiliarizam-se dos conceitos gerais de direito internacional ${ }^{22}$.

Koskenniemi, na mesma linha, ressalta que "nenhum regime é inteiramente autocontido" 23 , e indica que mesmo nos casos de regimes autocontidos bem desenvolvidos, o direito geral não deixa de operar.

Nesse contexto, a controvérsia que circunda a OMC relaciona-se à sua limitação, particularmente quando da resolução de seus litígios pelo seu mecanismo de resolução de controvérsias, em aplicar normas não oriundas da organização como fonte de direito. A razão para essa limitação, além dos fatores já mencionados nesta seção, encontra raízes nos próprios textos que delineiam o procedimento a ser seguido quando da provocação do MSC por um Membro da Organização.

\section{APONTAMENTOS NORMATIVOS: AS DISPOSIÇÕES DO ESC SOBRE 0 DIREITO APLICÁVEL À OMC}

Sendo o sistema judicante o principal lócus de aplicação do direito de um ordenamento, corolário que apenas as normas que possam ser invocadas dentro do órgão judicante desse ordenamento reflitam efetivamente as fontes de seu direito aplicável ${ }^{24}$. No âmbito da OMC, o texto que rege o procedimento dentro do Mecanismo de Solução de Controvérsias (MSC) é o Anexo 2 do Acordo da OMC, o Entendimento Relativo às Normas e Procedimentos sobre Solução

\footnotetext{
${ }^{21}$ Os autores consideram: "First, the notion of 'self-contained regimes' has been misconceived as an argument in favour of entirely autonomous legal subsystems. Social systems cannot exist in splendid isolation from their environment." (SIMMA; PULKOWSKI, op. cit., p. 492).

${ }^{22}$ TREVES, Tullio. Fragmentation of International Law: The Judicial Perspective. Agenda Internacional, Peru, v. 27, n. 1, p.213-253, mar. 2009, p. 216

${ }^{23}$ Do original: "Yet, however, no legal regime is fully self-contained" (KOSKENNIEMI, op. cit., p. 10, traduzido).

${ }^{24}$ No mesmo sentido advogam Lindroos e Mehling, op. cit., p. 860.
} 
UM REGIME AUTOCONTIDO? APONTAMENTOS SOBRE O DIREITO APLICÁVEL AOS CONTENCIOSOS NO ÂMBITO DA OMC

ARNo DAL RI JÚNIOR, MARIANA CLARA DE ANDRADE

de Controvérsias (ESC), e o seu Artigo 1:1 é claro ao dispor que “[a]s regras e procedimentos do presente Entendimento se aplicam às controvérsias pleiteadas conforme as disposições sobre consultas e solução de controvérsias dos acordos enumerados no Apêndice 1 do presente Entendimento"25.

Os textos enumerados no Apêndice 1 acima referido pelo ESC, denominados de acordos abrangidos, incluem apenas o Acordo Constitutivo da OMC e seus Anexos 1, 2 e $4^{26}$. Em um primeiro olhar, isso significa que obrigações firmadas por acordos "não abrangidos", em tese, não serão apreciadas dentro do MSC/OMC.

Contudo, diversos autores se opõem a essa argumentação, de modo que, hodiernamente, majoritariamente se concorda que a OMC não é um circuito legal inteiramente fechado ${ }^{27}$.

Mavroidis e Palmeter argumentam que os acordos abrangidos não exaurem as fontes de direito a serem consideradas pela $\mathrm{OMC}^{28}$. Em sentido análogo, Van Den Bossche reconhece que a principal fonte do sistema jurídico da OMC efetivamente é o Acordo da OMC; contudo, ele enumera ainda outras fontes de direito da OMC, como as decisões do seu OSC, demais acordos concluídos no âmbito da organização, atos dos órgãos da OMC além do próprio direito internacional costumeiro, princípios gerais do direito e outros acordos internacionais ${ }^{29}$.

Pauwelyn, por sua vez, defende que, ainda que as normas do sistema multilateral de comércio sejam consideradas parte de um ramo do direito internacional público (e um ramo especializado, que em certa medida inclusive constitui lex specialis em face de algumas - não todas - as normas de direito internacional), não podem ser vistas como um sistema à parte do direito internacional ${ }^{30}$.

Efetivamente, ainda que se considere a possibilidade de o sistema judicante da OMC aplicar apenas as normas concluídas dentro do espectro do seu próprio sistema, a regulação do

\footnotetext{
${ }^{25}$ BRASIL. Ministério do Desenvolvimento, Indústria e Comércio Exterior (MDIC). Entendimento Relativo às Normas e Procedimentos sobre Solução de Controvérsias (ESC).

${ }^{26}$ Cabe relembrar que os Anexos 1 e 4 referem-se aos Acordos comerciais multilaterais e plurilaterais, respectivamente, e o Anexo 3 refere-se ao próprio Entendimento relativo às Normas e Procedimentos sobre Solução de Controvérsias (ESC).

${ }^{27}$ LINDROOS; MEHLING, op. cit., p. 858.

${ }^{28}$ MAVROIDIS; PALMETER, op. cit, p. 399.

${ }^{29}$ Segundo o autor: "The principal source of WTO law is the Marrakesh Agreement Establishing the World Trade Organization, concluded on 15 April 1994 and in force since 1 January 1995. Other sources of WTO law include WTO dispute settlement reports, acts of WTO bodies, agreements concluded in the context of the WTO, customary international law, general principles of law, other international agreements, subsequent practice of WTO Members, teachings of the most highly qualified publicists and, finally, the negotiating history" (VAN DEN BOSSCHE, op. cit., p. 44).

30 PAUWELYN, Joost. The Role of Public International Law in the WTO: How Far Can We Go?. American Journal of International Law, v. 95, pp. 535-578, 2001, p. 539.
} 
UM REGIME AUTOCONTIDO? APONTAMENTOS SOBRE O DIREITO APLICÁVEL AOS CONTENCIOSOS NO ÂMBITO DA OMC

ARNo DAL RI JÚNIOR, MARIANA CLARA DE ANDRADE

sistema multilateral de comércio acaba por afetar, direta ou indiretamente, outros campos do direito internacional. Nesse sentido, Marceau menciona inclusive que as próprias exceções do Artigo XX do GATT/94 31 , ao tratar sobre situações como proteção ao meio ambiente, saúde e segurança, reconhece a existência de outros sistemas de direito e política regulatória ${ }^{32}$. Se a interpretação do direito da OMC fosse efetivada em completo isolamento do direito internacional geral, como se a organização fosse um sistema jurídico completamente autônomo e à parte dessa relação, conflitos com outras normas seriam mais suscetíveis de ocorrer ${ }^{33}$.

Koskenniemi, ademais, ressalta que um conjunto de normas não pode ser considerado especial ou geral abstratamente - essa é uma definição relativa (e relacional) ${ }^{34}$. Assim sendo, é de se inferir que não há elementos que indiquem a primazia das normas da OMC, pelo critério da especialidade, perante toda e qualquer outra norma de direito internacional.

Para respaldar normativamente a leitura de que a OMC não é um regime completamente isolado, alguns autores argumentam que os Artigos 3.2 e 7 do ESC positivam a abertura do sistema, expandindo o arcabouço normativo a priori designado pelo supracitado Artigo 1.1 do mesmo texto ${ }^{35}$. Particularmente, assim dispõe o Artigo 3.2:

2. O sistema de solução de controvérsia da OMC é elemento essencial para trazer segurança e previsibilidade ao sistema multilateral de comércio. Os Membros reconhecem que esse sistema é útil para preservar direitos e obrigações dos Membros dentro dos parâmetros dos acordos abrangidos e para esclarecer as disposições vigentes dos referidos acordos em conformidade com as normas correntes de interpretação do direito internacional público. As recomendações e decisões do OSC não poderão promover o aumento ou a diminuição dos direitos e obrigações definidos nos acordos abrangidos. ${ }^{36}$

Este trecho, em sua redação original, faz menção expressa às normas costumeiras sobre interpretação do direito internacional público (em vez de "normas correntes de interpretação do direito internacional público") $)^{37}$. O Artigo 3.2 é frequentemente invocado pelo OAp em seus

${ }^{31}$ As Exceções Gerais do Artigo XX do GATT/94 escusam as obrigações acordadas pelos membros nesse texto em prol de algumas hipóteses taxativamente descritas em suas alíneas, tais como a proteção ambiental, a saúde humana, o patrimônio histórico, a moral pública, dentre outras.

32 MARCEAU, Gabrielle Zoe. A call for coherence in international law: praises for the prohibition against "Clinical Isolation" in WTO dispute settlement. Journal of World Trade, Great Britain, v. 33, n. 5, p. 87152, 1999, p. 108.

${ }^{33}$ MARCEAU, idem, p. 109.

${ }^{34}$ KOSKENIEMMI, op. cit., p. 5

${ }^{35}$ MAVROIDIS; PALMETER, op. cit., p. 399

36 BRASIL, op. cit, grifo acrescido.

${ }^{37}$ No original: "2. The dispute settlement system of the WTO is a central element in providing security and predictability to the multilateral trading system. The Members recognize that it serves to preserve the rights and obligations of Members under the covered agreements, and to clarify the existing provisions of those agreements in accordance with customary rules of interpretation of public 
UM REGIME AUTOCONTIDO? APONTAMENTOS SOBRE O DIREITO APLICÁVEL AOS CONTENCIOSOS NO ÂMBITO DA OMC

ARNo DAL RI JÚNIOR, MARIANA CLARA DE ANDRADE

julgados quando o órgão deseja fazer uso da metodologia interpretativa positivada pela Convenção de Viena Sobre o Direito dos Tratados $(C V D T)^{38}$, particularmente por ser tal Convenção considerada a positivação das normas costumeiras de interpretação ${ }^{39}$. Há, contudo, divergências doutrinárias acerca da sua extensão também com relação a outros tipos de normas de direito internacional enquanto parte da OMC.

O Artigo 7, por sua vez, é mais discutível. Faz-se pertinente sua transcrição para análise:

1. Os termos de referência dos grupos especiais serão os seguintes, a menos que as partes envolvidas na controvérsia acordem diferentemente dentro do prazo de 20 dias a partir da data de estabelecimento do grupo especial:

"Examinar, à luz das disposições pertinentes no (indicar o(s) acordo(s) abrangido(s) citado(s) pelas partes em controvérsia), a questão submetida ao OSC por (nome da parte) no documento . estabelecer conclusões que auxiliem o OSC a fazer recomendações ou emitir decisões previstas naquele(s) acordo(s)".

2. Os grupos especiais deverão considerar as disposições relevantes de todo acordo ou acordos abrangidos invocados pelas partes envolvidas na controvérsia.

3. Ao estabelecer um grupo especial, o OSC poderá autorizar seu Presidente a redigir os termos de referência do grupo especial com a colaboração das partes envolvidas na controvérsia, de acordo com as disposições do parágrafo 1. Os termos de referência assim redigidos serão distribuídos a todos os Membros. Caso os termos de referência sejam diferentes do padrão, qualquer Membro poderá levantar qualquer ponto a ele relativo no OSC. ${ }^{40}$

Considera-se ser tal artigo mais controverso, pois, ao mesmo tempo em que autores como Mavroidis e Palmeter utilizam-no como um "substituto, mutatis mutandis, do Artigo 38 [do Estatuto da Corte Internacional de Justiça $\left.{ }^{41}\right]^{\text {"42 }}$, outros autores, como Gabrielle Marceau, consideram-no como uma restrição ao mandato do $M S C / O M C^{43}$.

international law. Recommendations and rulings of the DSB cannot add to or diminish the rights and obligations provided in the covered agreements" (grifo acrescido). Fonte: < http://www.wto.org/english/tratop_e/dispu_e/dsu_e.htm\#4>. Acesso em 26/09/2014.

${ }^{38}$ Cameron e Gray afirmam ter havido uma aceitação tácita da aplicação da CVDT para a interpretação por meio do Artigo 3.2 do ESC (CAMERON; GRAY, op. cit, p. 253). Os autores lembram ainda que as normas da convenção podem ser usadas para interpretação inclusive com relação a países litigantes no MSC não membros da CVDT, pois suas provisões representam uma codificação do direito costumeiro internacional e, portanto, são vinculantes a todos os Estados, conforme ressaltou o OAp em Japan -Taxes (CAMERON; GRAY, op. cit., p. 254).

${ }^{39}$ Esse foi o entendimento consolidado pelo OAp no casos US - Reformulated gasoline (WT/DS2/AB/R, p. 17)

${ }^{40}$ BRASIL, op. cit., grifo acrescido.

${ }^{41} \mathrm{O}$ artigo $38(1)$ do Estatuto da CIJ enumera as fontes de direito que poderão ser analisadas pelo Tribunal.

42 Traduzido do original: "This paper views Article 7 of the DSU as the WTO substitute, mutatis mutandis, for Article 38. From this perspective, it considers, as sources of law, the texts of the WTO Agreements; panel and Appellate Body reports interpreting "the relevant provisions" of those 
UM REGIME AUTOCONTIDO? APONTAMENTOS SOBRE O DIREITO APLICÁVEL AOS CONTENCIOSOS NO ÂMBITO DA OMC

ARNo DAL RI JÚNIOR, MARIANA CLARA DE ANDRADE

Marceau reconhece que o mecanismo de resolução de litígios da OMC não é uma corte de direito internacional geral. Como mencionado, ela indica que o próprio Artigo 7.2, além do Artigo 11, do ESC são claros ao limitar a competência dos painéis à aplicabilidade e conformidade com os acordos abrangidos relevantes. Apesar disso, ela defende a possibilidade de interpretação de normas externas, ainda que não seja possível a adjudicação das suas obrigações ${ }^{44}$.

Outra forma de análise do Artigo 7 argumenta que as disposições supratranscritas não limitam o direito aplicável nos contenciosos da OMC aos acordos abrangidos ${ }^{45}$. Bartels, nessa linha, enfatiza a utilização da expressão "à luz das disposições pertinentes no acordo abrangido" para argumentar que a utilização dos acordos permitidos pelo Artigo 1.1 do ESC não é a única fonte de direito a ser considerada pelos painéis ${ }^{46}$. Na mesma linha, o autor defende que o Artigo 7.2 pode ser interpretado de maneira igualmente ampla, pois não há qualquer proibição à utilização de outras fontes de direito quando da resolução de um litígio ${ }^{47}$.

A lógica apresentada por Bartels para a leitura dos Artigos 3.2 e 7 do ESC pode, em realidade, ser transladada para todas as disposições do Entendimento uma vez que, ainda que expressamente seja mencionada a referibilidade a acordos abrangidos como direito aplicável, em nenhum momento os textos da $\mathrm{OMC}$ os restringem como única fonte aplicável.

De todo modo, o próprio OAp considerou que o Artigo 3.2 reflete o não isolamento do sistema OMC do direito internacional público. No caso US - Reformulated Gasoline, o OAp entendeu que, ao autorizar-se o uso direito consuetudinário internacional, "o GATT [ou o próprio direito da $\mathrm{OMC}]$ não pode ser lido em isolamento clínico do direito internacional público"48.

Agreements, as that term is used in Article 7; custom; the teachings of publicists; general principles of law; and other international instruments" (MAVROIDIS; PALMETER, op. cit., p. 399, grifo acrescido).

${ }^{43}$ MARCEAU, op. cit., p. 110.

${ }^{44}$ Idem, p. 110.

${ }^{45}$ Cf. PALMETER; MAVROIDIS, op. cit., p. 399; BARTELS, op. cit., p. 504.

${ }^{46} \mathrm{O}$ autor observa: "Nowhere do these paragraphs say that the law applicable in Panel proceedings is limited to that contained in the covered agreements. According to Article 7.1, Panels are to examine the matter referred to the DSB by the complainant in the light of the relevant provisions in the relevant covered agreement. The phrase "in the light of" does not limit the sources of law that might be relevant in examining the "matter"." (BARTELS, op. cit., p. 505).

${ }^{47}$ BARTELS, op. cit., p. 505.

${ }^{48}$ No original: "The 'general rule of interpretation' set out above has been relied upon by all of the participants and third participants, although not always in relation to the same issue. That general rule of interpretation has attained the status of a rule of customary or general international law. As such, it forms part of the 'customary rules of interpretation of public international law' which the Appellate Body has been directed, by Article 3(2) of the DSU, to apply in seeking to clarify the provisions of the General Agreement and the other 'covered agreements' of the Marrakesh Agreement Establishing the World Trade Organization (the 'WTO Agreement'). That direction reflects a measure of recognition that 
UM REGIME AUTOCONTIDO? APONTAMENTOS SOBRE O DIREITO APLICÁVEL AOS CONTENCIOSOS NO ÂMBITO DA OMC

ARNo DAL RI JÚNIOR, MARIANA CLARA DE ANDRADE

No mesmo sentido, Pauwelyn relembra a própria presunção inserida na lógica do direito internacional de que se um tratado não derroga outra norma de direito internacional geral, aquela norma continua a ser direito aplicável. A partir disso, o autor argumenta que, se essa presunção não é suficiente para comprovar que o sistema da OMC não é um regime fechado, o Artigo 3.2 corrobora essa leitura ${ }^{49}$.

A CVDT, norma que reconhecidamente positiva as normas costumeiras de interpretação do direito internacional, dispõe, em seu Artigo 31.3:

3. Serão levados em consideração, juntamente com o contexto:

a)qualquer acordo posterior entre as partes relativo à interpretação do tratado ou à aplicação de suas disposições;

b)qualquer prática seguida posteriormente na aplicação do tratado, pela qual se estabeleça o acordo das partes relativo à sua interpretação;

c)quaisquer regras pertinentes de Direito Internacional aplicáveis às relações entre as partes. ${ }^{50}$

O parágrafo (c) é claro ao dispor que quaisquer regras de Direito Internacional aplicáveis às relações entre as partes devem ser levadas em consideração quando da interpretação de um texto de direito internacional. Por conseguinte, a própria Convenção já recorrentemente utilizada como suporte interpretativo pelo MSC da OMC indica expressamente a possibilidade de interação com quaisquer normas de direito internacional geral. Em outras palavras, se tratados fora do âmbito do sistema OMC também são aplicáveis à relação discutida, ou mesmo se princípios ou o costume internacional são passíveis de serem invocados, tais elementos devem ser analisados pelo MSC/OMC quando da resolução de um litígio.

A aplicabilidade dessas demais normas, particularmente outros acordos internacionais, enquanto fonte de direito à interpretação das obrigações da OMC não parece ser objeto de controvérsia, mesmo porque de tal recurso já lançou mão o próprio OAp em diversos $\operatorname{casos}^{51}$. Contudo, a análise das obrigações assumidas fora da OMC pelo MSC e sua possível vinculação pelo Órgão de Solução de Controvérsias é o objeto de maior debate doutrinário.

Essa discussão acerca da interação das obrigações da OMC com o direito externo remonta à separação conceitual entre o direito aplicável e a competência (do inglês, "jurisdiction") do MSC, recorrentemente tratada pelos autores que se debruçam sobre essa

the General Agreement is not to be read in clinical isolation from public international law." (WT/DS2/AB/R, 1996, p. 17).

${ }^{49}$ PAUWELYN, op. cit., p. 542.

${ }^{50}$ BRASIL, op. cit..

${ }^{51} \mathrm{Cf}$, e.g., os casos trazidos pela seção 3 deste Artigo. 
UM REGIME AUTOCONTIDO? APONTAMENTOS SOBRE O DIREITO APLICÁVEL AOS CONTENCIOSOS NO ÂMBITO DA OMC

ARno DAL RI JÚNIOR, MARIANA CLARA dE ANDRADE

debate $^{52}$. Para Bartels, a competência do MSC/OMC está descrita e limitada no Artigo 1.1 do ESC, de modo que o direito vinculante analisado por painéis e pelo OAp é aquele disposto pelos acordos abrangidos. Contudo, segundo o autor, para o exercício dessa competência, nada impede que outras fontes de direito internacional sejam consideradas como direito aplicável ${ }^{53}$.

Bartels traz à discussão ainda a leitura do Artigo 19.2 do ESC, que dispõe sobre a limitação da utilização das normas costumeiras permitida pelo Art. 3.2 do ESC ${ }^{54}$, pois “as conclusões e recomendações do grupo especial e do Órgão de Apelação não poderão ampliar ou diminuir os direitos e obrigações derivados dos acordos abrangidos" ${ }^{25}$. Seu entendimento dessa leitura conjunta é de que todas as fontes de direito internacional são aplicáveis à OMC, mas sua interpretação não pode modificar os direitos e obrigações do direito da OMC.

Assim, Bartels defende que a competência dos grupos especiais e do Órgão de Apelação não se confunde com o direito aplicável às disputas ${ }^{56}$. Diversas fontes de direito internacional podem ser utilizadas para definir os limites das obrigações estabelecidas pelos acordos abrangidos $^{57}$. Ainda para Bartels, o Artigo 19.2 do ESC constitui, portanto, uma limitação à incorporação de direito externo à OMC, de modo que o MSC não poderá aplicar normas externas se isso resultar em uma modificação nos direitos e obrigações dos membros da organização ${ }^{58}$.

Além dessa distinção entre direito aplicável e competência do MSC/OMC, Pauwelyn considera uma distinção entre o direito aplicável e a referência a normas externas à OMC enquanto evidências factuais. $\mathrm{O}$ autor indica que alguns aspectos de normas externas à OMC, particularmente tratados, podem ser analisados pelos painéis como indícios das alegações factuais das partes ${ }^{59}$. Um exemplo utilizado por Pauwelyn é, no âmbito da análise do Artigo XX (b), a medida restritiva ao comércio imposta por um Acordo Multilateral Ambiental (MEA) diversamente difundido na comunidade internacional pode corroborar o entendimento de que

${ }^{52}$ Cf., e.g., PAUWELYN, 2003, p. 441 e ss.; LINDROOS E MEHLING, 2006, p. 860 e ss.; BARTELS, 2001 , p. 501 e ss.; TREVES, 2009, p. 240.

53 BARTELS, Applicable Law in WTO Dispute Settlement Proceedings. Journal Of World Trade Law, The Netherlands, v. 35, n. 3, p.499-519, mar. 2001, p. 503 e ss.

${ }^{54}$ BARTELS, idem, p. 507.

55 BRASIL, op. cit. .

${ }^{56}$ BARTELS, op. cit., p. 502-503.

57 Esse entendimento é contra-arrazoado por Pauwelyn, que defende que os Artigos 3.2 e 19.2 não constituem cláusulas de conflito ("conflict clauses") (PAUWELYN, Joost. Conflict of Norms in Public International Law: How WTO Law Relates to other Rules of International Law. New York: Cambridge University Press, 2003, pp. 352 e ss.).

${ }^{58}$ BARTELS, Lorand. Jurisdiction and Applicable Law in the WTO. Cambridge: Cambridge University Press, 2014, p. 22

${ }^{59}$ PAUWELYN, Joost. Conflict of Norms in Public International Law: How WTO Law Relates to other Rules of International Law. New York: Cambridge University Press, 2003, p. 463 
UM REGIME AUTOCONTIDO? APONTAMENTOS SOBRE O DIREITO APLICÁVEL AOS CONTENCIOSOS NO ÂMBITO DA OMC

ARno Dal RI JÚNIOR, MARIANA CLARA DE ANDRADE

aquela medida restritiva é “necessária à preservação dos vegetais”, como demanda a referida alínea. Contudo, o autor vai além e argumenta que se a existência de um MEA pode servir de base para “absolver” um membro da OMC conforme as Exceções Gerais, esse tratado alienígena perpassa o respaldo fático da defesa e serve também como base legal válida para os argumentos daquele membro ${ }^{60}$.

Observe-se que a utilização de uma norma internacional exterior à OMC como fundamento das escusas do Artigo XX - portanto, como direito aplicável - não é contrário ao entendimento de que a competência do MSC está pautada unicamente nos acordos abrangidos. Se um grupo especial ou o OAp entender, com base (fática ou jurídica) em um MEA, que o membro reclamado está exonerado de suas obrigações perante o GATT/94 em análise das alíneas e do caput do Artigo XX, ele não o faz com respaldo normativo nesse MEA, mas nas próprias Exceções Gerais.

Em outras palavras, essa leitura não se confunde com a sugestão de que o Órgão de Solução de Controvérsias teria poder para vincular as partes litigantes a conformar-se às disposições do referido acordo externo, e.g. uma convenção em matéria ambiental. A exoneração das obrigações para com o GATT/94 não traria a obrigação de uma parte de impor restrições ao comércio determinadas por referida convenção.

Marceau, por sua vez, também contra essa tendência de "isolamento clínico" já mencionada propõe que o MSC pode utilizar-se de demais normas de direito internacional para interpretar as disposições da OMC - mesmo porque é desta forma que dispõe o já mencionado Artigo 31.3(c) da Convenção de Viena de $1969^{61}$. A autora defende que essa interpretação deve levar em consideração normas externas ao direito da OMC “no limite necessário para dispor da matéria em análise" ${ }^{62}$. Marceau é clara em limitar essa interação à mera interpretação das obrigações da OMC, considerando que "a OMC não é uma corte de jurisdição geral"63.

\footnotetext{
${ }^{60}$ PAUWELYN, idem, p. 465.

${ }^{61}$ MARCEAU, Gabrielle Zoe. A call for coherence in international law: praises for the prohibition against "Clinical Isolation" in WTO dispute settlement. Journal of World Trade, Great Britain, v. 33, n. 5, p. 87 152, 1999, passim.

${ }^{62}$ Traduzido do original: "The implication is that their role is limited to interpreting the non-WTO rule to the extent necessary to dispose of the matter at hand" (MARCEAU, op. cit., p. 134).

${ }^{63}$ No original: "The WTO is not a court of general jurisdiction" (MARCEAU, idem, p. 109). Em síntese, a autora defende que "While non-WTO legal rules may be used when interpreting and applying WTO provisions, the specific and circumscribed mandate and jurisdiction of WTO adjudicating bodies does not extend so far as to permit them to enforce independent rights and obligations embodied in public international law" (MARCEAU, idem, p. 107).
} 
UM REGIME AUTOCONTIDO? APONTAMENTOS SOBRE O DIREITO APLICÁVEL AOS CONTENCIOSOS NO ÂMBITO DA OMC

ARNo DAL RI JÚNIOR, MARIANA CLARA DE ANDRADE

Por fim, é relevante mencionar o entendimento de Mavroidis em seu trabalho Remédios no Sistema Jurídico da $O M C^{64}$ em que o autor analisa os remédios no sistema jurídico da OMC, particularmente com relação aos Draft Articles sobre responsabilidade internacional da Comissão de Direito Internacional ${ }^{65}$. Apesar de abordar precipuamente, nesse artigo, o efeito jurídico das decisões do OSC, o autor realiza uma análise conjunta com as disposições sobre responsabilidade por descumprimento de obrigações internacionais no supramencionado acordo.

Ao fazer essa ponte, o autor é claro ao ressaltar que "um recurso deve (...) ser feito à codificação da ILC [International Law Commission, ou CDI] somente até onde um regime de tratado particular não contenha disposições específicas sobre o tema dos remédios jurídicos", e complementa que "[o] regime da OMC é vago sobre esse assunto" ${ }^{66}$. Assim sendo, Mavroidis sugere que os remédios jurídicos ao descumprimento das obrigações da OMC podem levar em consideração as formas de reparação de dano e cessação da ilegalidade postas pelo direito consuetudinário (e refletidos no projeto de artigos da CDI) ${ }^{67}$.

Essa leitura é interessante por ir além da questão do direito aplicável no momento de se dirimir o litígio - também se pode considerar a verificação de normas externas ao direito da OMC quando da devida adequação de medidas consideradas incompatíveis com os acordos abrangidos.

O ESC de fato não traz uma vedação expressa com relação às normas e ao direito que pode ser apreciado pelo MSC nem invocado pelas partes. Apesar disso, todo o texto do Entendimento pauta-se nos direitos e obrigações dispostos pelos acordos abrangidos, constantemente vinculando tanto os grupos especiais como o próprio OSC diretamente a esses textos $^{68}$. Infere-se uma espécie de prevalência de tais normas sobre outras quando da sua

\footnotetext{
${ }^{64}$ MAVROIDIS, Petros C.. Remédios no Sistema Jurídico da OMC: Entre um Rochedo e um Lugar Difícil. Tradução de: Ciro Mioranza. In: RI JÚNIOR, Arno dal; OLIVEIRA, Odete Maria de (Org.). Direito Internacional Econômico em Expansão: Desafios e Dilemas. Ijuí: Unijuí, 2003. p. 229-231.

${ }^{65}$ A Comissão de Direito Internacional (CDI) é um órgão vinculado à Assembleia Geral das Nações Unidas para realizar a codificação das normas costumeiras de direito internacional. 0 chamado Projeto da Comissão de Direito Internacional das Nações Unidas sobre Responsabilidade Internacional dos Estados é a positivação, ainda não transformada em convenção internacional, sobre a responsabilidade internacional por ato ilícito dos Estados. Disponível em: <http://iusgentium.ufsc.br/wpcontent/uploads/2015/09/Projeto-da-CDI-sobre-Responsabilidade-Internacional-dos-Estados.pdf>.

Tradução: Prof. Dr. Aziz Tuffi Saliba. Acesso em 15/04/2016.

${ }^{66}$ MAVROIDIS, 2003, pp.231-232.

${ }^{67}$ Mavroidis escreve: "Na segunda frase do Artigo 19(1), o DSU não prejulga a forma dos remédios jurídicos que os órgãos competentes da OMC possam sugerir. Até onde, consequentemente, o regime da OMC não fornece remédios específicos, a codificação da ILC é relevante" (MAVROIDIS, op. cit., p. 232).

${ }^{68}$ Cf., e.g., além dos artigos já citados, o Artigo 3.4 ("As recomendações ou decisões formuladas pelo OSC terão por objetivo encontrar solução satisfatória para a matéria em questão, de acordo com os direitos e obrigações emanados pelo presente Entendimento e pelos acordos abrangidos") e o Artigo 3.5 ("Todas as soluções das questões formalmente pleiteadas ao amparo das disposições sobre consultas e solução de
} 
UM REGIME AUTOCONTIDO? APONTAMENTOS SOBRE O DIREITO APLICÁVEL AOS CONTENCIOSOS NO ÂMBITO DA OMC

ARNo DAL RI JÚNIOR, MARIANA CLARA DE ANDRADE

adjudicação dentro do sistema $\mathrm{OMC}^{69}$, ainda que elas possam ser levadas em consideração enquanto direito aplicável. Um tratado comum às partes litigantes e que imponha restrições conflitantes com a cláusula da Nação-Mais-Favorecida, por exemplo, poderá ser invocado como direito aplicável e considerado pelo painel formado para o litígio, mas a obrigação em análise continuará sendo aquela disposta pelo Artigo I do GATT/94.

\section{APONTAMENTOS JURISPRUDENCIAIS: INDÍCIOS ${ }^{70}$ PRAGMÁTICOS}

O objetivo da análise que será traçada a seguir é verificar de que maneira as decisões prolatadas nos contenciosos levados à OMC têm tratado o tema, a fim de se extrair conclusões mais pragmáticas para a presente problemática.

Conforme mencionado, o OAp, no caso US - Reformulated Gasoline, de 1996, postulou que o GATT não deveria ser examinado em “isolamento clínico" do direito internacional geral. 0 contexto em que essa assertiva foi realizada é extremamente pertinente.

O OAp, ao revisar a aplicação do Artigo XX(g) realizada pelo grupo especial no caso em questão, entendeu que uma "norma fundamental de interpretação de tratados"71 tinha sido subjulgada; esta norma fundamental tinha inclusive sido positivada pela CVTD. Ao mencionar o Artigo 31(1) da referida Convenção - a "regra geral de interpretação"72, o OAp indicou que essa norma teria "adquirido status de regra costumeira ou de direito internacional geral"73, nos termos do Artigo 3.2 do ESC.

O OAp indicou ainda que o Artigo 3.2 do ESC direciona-o a aplicar as normas costumeiras de interpretação de direito internacional público a fim de esclarecer as provisões do GATT e

controvérsias, incluindo os laudos arbitrais, deverão ser compatíveis com aqueles acordos e não deverão anular ou prejudicar os benefícios de qualquer Membro em virtude daqueles acordos, nem impedir a consecução de qualquer objetivo daqueles acordos") (MDIC, ESC).

${ }^{69}$ Pauwelyn apresenta opinião divergente: PAUWELYN, Joost. Conflict of Norms in Public International Law: How WTO Law Relates to other Rules of International Law. New York: Cambridge University Press, 2003, p. 491.

${ }^{70}$ Utiliza-se do termo indícios para intitular esta seção uma vez que, como anteriormente mencionado, não há uma resposta inequívoca para a questão averiguada por este trabalho - que vem intensificada pela atualidade do tema.

${ }^{71}$ WT/DS2/AB/R. United States - Standards for Reformulated and Conventional Gasoline, 1996, p. 17

72 Assim dispõe o mencionado dispositivo: "1. Um tratado deve ser interpretado de boa fé segundo o sentido comum atribuível aos termos do tratado em seu contexto e à luz de seu objetivo e finalidade". (BRASIL. Convenção de Viena Sobre O Direito dos Tratados: DECRETO № 7.030, DE 14 DE DEZEMBRO DE 2009. Brasília, 2009).

${ }^{73}$ No original: "That general rule of interpretation has attained the status of a rule of customary or general international law" (WT/DS2/AB/R, p. 17). 
UM REGIME AUTOCONTIDO? APONTAMENTOS SOBRE O DIREITO APLICÁVEL AOS CONTENCIOSOS NO ÂMBITO DA OMC

ARno Dal RI JÚNIOR, MARIANA CLARA DE ANDRADE

outros acordos abrangidos. E, nessa lógica, destacou: "Esse direcionamento reflete uma medida de reconhecimento de que o Acordo Geral [GATT] não deve ser lido em isolamento clínico do direito internacional público"74.

Duas considerações podem ser feitas acerca dessa passagem. A primeira, já brevemente comentada, é que essa leitura corrobora o entendimento defendido por alguns autores de que o Artigo 3.2 representa a válvula de escape positivada do sistema da OMC para a sua interação com as demais normas de direito internacional.

A própria escolha de palavras do OAp passa a impressão de ser mais abrangente do que o próprio texto do Artigo 3.2 - ao utilizar o termo lido em detrimento do termo meramente interpretado, aparentemente o Órgão veda o “isolamento clínico" para além da mera interpretação dos termos do tratado e seu objetivo e propósito. De todo modo, essa adução não encontra respaldo mais palpável, pois esta é a única passagem dessa decisão em que o OAp trata da interação das normas da OMC com o direito internacional geral.

A segunda conclusão também envolve a escolha de palavras utilizada pelo OAp, ao indicar que a regra geral de interpretação em questão atingira o "status de norma de direito costumeiro ou direito internacional geral"75. O conectivo ou dá margem ao entendimento de que não apenas normas consuetudinárias, como outras normas de direito internacional geral (e.g., princípios) poderiam ser consideradas quando da interpretação dos acordos abrangidos. Apesar disso, essa mesma abertura é imprecisa, ao não desenvolver o conceito de direito internacional geral.

Finalmente, cabe mencionar que, para respaldar o entendimento de que a CVDT obteve status de norma costumeira, o OAp mencionou uma série de outras decisões fora do âmbito do MSC/OMC (incluindo a Corte Europeia de Direitos Humanos e a Corte Internacional de Justiça), bem como considerações doutrinárias ${ }^{76}$. Essas menções também demonstram que o OAp não está completamente alheio ao que ocorre fora da sua própria jurisdição.

Apesar da ausência de respaldo normativo ou manifestação expressa por parte do OAp, tacitamente entende-se estar bem sedimentada a possibilidade de aplicação de normas de direito internacional geral (pelo menos o costumeiro) à interpretação das disposições dos

\footnotetext{
${ }^{74}$ No original: "That direction reflects a measure of recognition that the General Agreement is not to be read in clinical isolation from public international law" (WT/DS2/AB/R, p. 17).

${ }^{75}$ Grifo acrescido. Traduzido do original: "The "general rule of interpretation" set out above has been relied upon by all of the participants and third participants, although not always in relation to the same issue. That general rule of interpretation has attained the status of a rule of customary or general international law" (WT/DS2/AB/R, p. 17).

${ }^{76}$ WT/DS2/AB/R, p. 17
} 
UM REGIME AUTOCONTIDO? APONTAMENTOS SOBRE O DIREITO APLICÁVEL AOS CONTENCIOSOS NO ÂMBITO DA OMC

ARNo DAL RI JÚNIOR, MARIANA CLARA DE ANDRADE

acordos abrangidos. Contudo, há controvérsias sobre se o Artigo 3.2 limita-se a essa interpretação, ou se é um indício da abertura à interação das normas da OMC com as normas externas de modo geral. Acerca dos limites do Artigo 3.2 ao determinar a recorribilidade a normas costumeiras de direito internacional geral sobre a interpretação de tratados, o painel do caso Korea - Government Procurement assim se posicionou:

Nós consideramos que o Artigo 3.2 do ESC requer, no contexto de uma determinada disputa, a clarificação de provisões existentes dos acordos da OMC de acordo com regras costumeiras de interpretação de direito internacional público. Contudo, a relação dos Acordos da OMC com relação ao direito consuetudinário internacional é mais ampla do que isso. 0 costume internacional aplica-se genericamente às relações econômicas entre membros da OMC. Esse direito internacional aplica-se até o limite em que os acordos da OMC não o derroguem. Em outras palavras, até o limite em que não haja conflito ou inconsistência, ou uma expressão em um acordo abrangido que seja contraditória, nós somos do entendimento de que regras costumeiras de direito internacional aplicam-se a tratados da OMC e ao processo de formação de tratados dentro da OMC. ${ }^{77}$

As partes litigantes, neste caso, decidiram por não apelar da decisão do painel ${ }^{78}$, de modo que não pode ser confirmada ou reformada pelo OAp. Assim, embora essa decisão não tenha a força interpretativa que o OAp poder-lhe-ia conferir, serve a demonstrar o raciocínio jurídico que pauta determinados painelistas no confronto dos ordenamentos.

Conforme se verifica, a relação entre as obrigações firmadas por acordos externos e acordos da OMC não está clarificada. De igual maneira, outras fontes de direito internacional geral, tais como princípios e o costume, são aplicados de maneira bastante estrita pelos grupos especiais e pelo OAp.

A título exemplificativo, lança-se mão do caso EC - Hormones, em que as Comunidades Europeias invocaram o princípio da precaução para a justificativa de sua medida restritiva ao

\footnotetext{
77 Traduzido do original: "We take note that Article 3.2 of the DSU requires that we seek within the context of a particular dispute to clarify the existing provisions of the WTO agreements in accordance with customary rules of interpretation of public international law. However, the relationship of the WTO Agreements to customary international law is broader than this. Customary international law applies generally to the economic relations between the WTO Members. Such international law applies to the extent that the WTO treaty agreements do not "contract out" from it. To put it another way, to the extent there is no conflict or inconsistency, or an expression in a covered WTO agreement that implies differently, we are of the view that the customary rules of international law apply to the WTO treaties and to the process of treaty formation under the WTO" (WT/DS163/R, p. 181, para. 7.93 e ss, notas de rodapé suprimidas).

${ }^{78}$ Fonte: ORGANIZAÇÃO MUNDIAL DO COMÉRCIO. Korea - Measures Affecting Government Procurement. Disponível em: <http://www.wto.org/english/tratop_e/dispu_e/cases_e/ds163_e.htm>. Acesso em: 29 jan. 2015.
} 
UM REGIME AUTOCONTIDO? APONTAMENTOS SOBRE O DIREITO APLICÁVEL AOS CONTENCIOSOS NO ÂMBITO DA OMC

ARNo DAL RI JÚNIOR, MARIANA CLARA DE ANDRADE

comércio $^{79}$. Contudo, o OAp entendeu que “o princípio da precaução, por si só e sem diretiva clara textual nesse sentido, não retira o encargo do painel do dever de aplicar os princípios normais (i.e. costume internacional) de interpretação de tratados ao analisar as disposições do Acordo SPS"80. Essa conclusão advém do entendimento de que o princípio da precaução estaria no âmbito dos princípios de direito internacional ambiental, sem que isso signifique que efetivamente seja um costume de direito internacional propriamente dito ${ }^{81}$, e, portanto, não vinculante ${ }^{82}$.

Em US - Shrimp, o OAp, ao analisar o caput do Artigo XX no caso, indicou que sua redação seria uma expressão do princípio da boa-fé, e invocou ainda a doutrina do abuso de direito ("abus de droit"), ambos expressão de princípios de direito internacional geral ${ }^{83}$. 0 OAp indicou ainda que sua tarefa seria "interpretar a linguagem do caput, buscando orientação interpretativa adicional, como apropriado, dos princípios gerais de direito internacional”84.

Curiosamente, distintamente do indicado no trecho transcrito, o princípio do desenvolvimento sustentável foi expressamente invocado pelo OAp nesse mesmo caso, mas o

79 No contexto do Acordo sobre a Aplicação de Medidas Sanitárias e Fitossanitárias (SPS), o acordo abrangido em análise no caso, é necessário que uma medida restritiva ao comércio esteja baseada em normas internacionais caso existam, ou justificação científica para tanto. Paralelamente, o Artigo 5.7 desse artigo permite que, nos casos de evidência científica insuficiente, um membro adote provisoriamente medidas com base na informação disponível. O uso do princípio da precaução, por sua vez, justificaria uma desnecessidade de acordo científico internacional sobre os riscos do consumo de carne com hormônios. Cf. WT/DS26/AB/R. European Communities - Measures Concerning Meat and Meat Products (Hormones). 1998, p. 46 e ss. e CAMERON, James; GRAY, Kevin R.. Principles of International Law in the WTO Dispute Settlement Body. International and Comparative Law Quarterly,Cambridge, v. 50, n. 02, pp. 248-298, abril 2001, p. 269.

${ }^{80}$ No original: "Lastly, however, the precautionary principle does not, by itself, and without a clear textual directive to that effect, relieve a panel from the duty of applying the normal (i.e. customary international law) principles of treaty interpretation in reading the provisions of the SPS Agreement". (WT/DS26/AB/R, p. 50, para. 124).

${ }^{81}$ Conforme o OAp: "The precautionary principle is regarded by some as having crystallized into a general principle of customary international environmental law. Whether it has been widely accepted by Members as a principle of general or customary international law appears less than clear. We consider, however, that it is unnecessary, and probably imprudent, for the Appellate Body in this appeal to take a position on this important, but abstract, question. We note that the panel itself did not make any definitive finding with regard to the status of the precautionary principle in international law and that the precautionary principle, at least outside the field of international environmental law, still awaits authoritative formulation". (WT/DS26/AB/R, p. 49, para. 123)

${ }^{82}$ KOSKENNIEMI; LEINO, op. cit., pp. 571-572. Sobre o tema, Koskenniemi e Leino observam: "suggesting that had it become customary, it would have been WTO-relevant" (KOSKENNIEMI; LEINO, op. cit., pp. 571-572).

${ }^{83}$ WT/DS58/AB/R. United States - Import Prohibition of Certain Shrimp and Shrimp Products. 1998, p. 62, para. 158.

${ }^{84}$ No original: "Having said this, our task here is to interpret the language of the chapeau, seeking additional interpretative guidance, as appropriate, from the general principles of international law" (WT/DS58/AB/R, p. 62, para. 158). 
UM REGIME AUTOCONTIDO? APONTAMENTOS SOBRE O DIREITO APLICÁVEL AOS CONTENCIOSOS NO ÂMBITO DA OMC

ARno DAL Ri JÚNIOR, MARIANA CLARa de ANDRAde

expresso recurso a ele foi feito a partir de sua positivação no Preâmbulo do Acordo Constitutivo da OMC (e, portanto, não ser exterior às normas da OMC).

Outro tópico de obscuridade relaciona-se com a aplicabilidade de outros tratados dentro do MSC. Cameron e Grey lembram que, no caso US -Tuna I, ainda na vigência do sistema de solução de controvérsias do GATT/47, o painel considerou que um Acordo Multilateral Ambiental poderia ser utilizado como base às Exceções Gerais do Artigo XX ${ }^{85}$.

O entendimento do caso US - Tuna I parece ser um exemplo claro da separação entre competência e direito aplicável a que se refere Bartels, como já mencionado. Ao utilizar-se de MEAs para verificar em que medida a proteção ambiental efetivamente é o objetivo perquirido por medidas restritivas ao comércio potencialmente justificáveis no âmbito do Artigo XX do GATT/94, um painel ou o Órgão de Apelação não estará vinculando as partes às obrigações contraídas por aquele acordo externo mas, meramente, com base no MEA, escusando as partes de suas obrigações perante o GATT/94.

Veja-se que essa distinção permite às partes litigantes trazerem ao MSC argumentos respaldados em normas externas à $O M C$, em contraposição à limitação que pode ser inferida em uma leitura estrita dos Artigos 1.1 e 7 do ESC.

O OAp também pouco se manifestou acerca da interação das obrigações concluídas pelos acordos abrangidos e aquelas concluídas em tratados externos à OMC. No caso EC Poultry, foi invocado um acordo bilateral negociado entre as partes litigantes, Brasil e Comunidades Europeias, como forma de resolução de um litígio anterior entre ambas ${ }^{86}$. Como o referido acordo bilateral não estava dentro do conceito de acordos abrangidos, o painel entendeu que não poderia configurar a base normativa para a disputa em questão, entendimento este mantido pelo $\mathrm{OAp}^{87}$. Considerando a existência de obrigações diretamente ligadas ao sistema OMC (no caso, o Schedule LXXX), o painel decidiu, portanto, utilizar-se de tais provisões, e o Acordo bilateral foi utilizado apenas como "meio suplementar de interpretação do Schedule LXXX, conforme Artigo 32 da Convenção de Viena"88. (cf. MARCEAU, 1999, p. 119).

\footnotetext{
${ }^{85}$ CAMERON; GRAY, op. cit., p. 265. Para uma análise de possíveis interações do Artigo XX com Acordos Multilaterais Ambientais (MEAs) com relação às partes na disputa, cf. MARCEAU, 1999, pp. 128 e ss.

${ }_{86} \mathrm{WT} / \mathrm{DS} 69 / \mathrm{AB} / \mathrm{R}$. European Communities - Measures Affecting Importation of Certain Poultry Products, 1998, p. 29, para. 79

$87 \mathrm{WT} / \mathrm{DS} 69 / \mathrm{AB} / \mathrm{R}$. European Communities - Measures Affecting Importation of Certain Poultry Products. 1998 , p. 30 , para. 81

${ }^{88}$ Do original: "Therefore, in our view, the Oilseeds Agreement may serve as a supplementary means of interpretation of Schedule LXXX pursuant to Article 32 of the Vienna Convention, as it is part of the
} 
ARNO DAL RI JÚNIOR, MARIANA CLARA DE ANDRADE

Esse caso demonstra a prevalência de uma norma do regime especial da OMC ser aplicada em detrimento de uma norma com a mesma possibilidade de subsunção, mas não integrada explicitamente pelo sistema de acordos abrangidos do ESC. Em EC - Poultry, o OAp manteve o entendimento do cabimento do exame do acordo bilateral externo à OMC apenas com o fim de verificar o histórico da conclusão do acordo parte da OMC - ou seja, uma aplicação interpretativa, ou subsidiária ao exame fático da questão.

Daí se infere que, na hipótese, e.g., de conflito entre uma obrigação imposta por um MEA e uma obrigação imposta por um acordo abrangido, o sistema de solução de litígios da OMC dará prevalência a esta última. A própria sugestão de que um MEA pode ser utilizado como respaldo fático-jurídico para averiguar as consistências do Artigo XX e suas alíneas, um mecanismo que trata de escusas às obrigações do GATT, indica a presunção de incompatibilidade com as suas disposições.

Há de se observar que essa situação não está relacionada ao fato de as normas da OMC serem mais específicas do que as do MEA ou outro acordo em questão, mas à sua competência. Como mencionado anteriormente, não há qualquer presunção que indique que as normas dos acordos abrangidos sejam prima facie lex specialis perante qualquer outra norma de direito internacional.

Tomando em consideração essa problemática, Sampson propõe que os países interessados negociem e delimitem amplamente os objetivos dessa regulação, de modo que uma eventual ilegalidade seja enfrentada a partir de um mecanismo desse próprio acordo, e não deixada à interpretação do MSC/OMC. O autor considera que, para tanto, é necessário que o MEA seja cuidadosamente redigido ${ }^{89}$.

Essa proposição realizada por Sampson corrobora a propensão a se crer que os acordos abrangidos têm prevalência sobre as normas externas dentro da jurisdição do MSC (o que retoma a distinção acima mencionada entre competência e direito aplicável).

Por fim, anota-se a existência de certa discricionariedade com relação à aplicação de princípios e costumes de direito internacional por parte dos painéis e OAp, de modo que, na ausência de esclarecimento jurisprudencial ou normativo inequívoco, fontes de direito internacional geral serão analisadas com maior discricionariedade pelo MSC.

historical background of the concessions of the European Communities for frozen poultry meat" (WT/DS69/AB/R, p. 29, para. 83)

89 SAMPSON, Gary P.. The world trade organization and sustainable development. Hong Kong: United Nations University Press, 2005, p. 129. 


\section{CONCLUSÃO}

A partir das ponderações trazidas com a leitura dos dispositivos normativos, da jurisprudência e da doutrina relevante aos propósitos do presente trabalho, pode-se verificar que o sistema OMC não é absolutamente autocontido, mas se comunica com o direito internacional geral. Nesse sentido, a diferenciação entre as noções de competência (“jurisdiction”) e direito aplicável traz implicações relevantes para o estudo aqui abordado, uma vez que, muito embora as fontes de direito que podem ser levadas em consideração pelo MSC/OMC na análise dos contenciosos não se fixam aos acordos abrangidos, a competência vinculante desse mecanismo parece ser a eles limitada.

Assim como o Artigo 1.1 não estabelece uma vedação às fontes de direito que podem ser utilizadas para o esforço interpretativo dos grupos especiais e do Órgão de Apelação, o Artigo 3.2 confere uma explícita abertura do sistema OMC ao direito internacional geral, reconhecida inclusive pelo OAp em US - Reformulated Gasoline. Os Estados-membros da OMC podem concluir obrigações fora da organização que traduzem inconsistências com o sistema multilateral de comércio, de modo que o enfrentamento dessa interação, inclusive levando em conta os critérios lex specialis e lex posteriori, deve ser realizado pelo MSC/OMC.

Por outro lado, o mesmo Artigo 1.1, em conjunto com o Artigo 19.2, estabelece uma limitação à competência do MSC, de modo que apenas as obrigações dispostas pelos acordos abrangidos poderão vincular ou desvincular as partes litigantes.

Disso se conclui, também, que normas externas ao sistema poderão ser consideradas pela OMC, mas servirão apenas à análise das obrigações estabelecidas pelo seu próprio sistema. O exemplo mais contundente de tal situação é a possibilidade de exoneração das obrigações do GATT/94 pelas alíneas de seu Artigo XX a partir da análise de convenções internacionais ambientais que possam justificar a tomada de medidas que, de outro modo, seriam inconsistentes com as disposições do Acordo Geral.

Outrossim, conforme se verifica da prática dos painéis e do OAp ao não raramente invocar outras referências para além de seu acordos abrangidos na resolução dos contenciosos, não parece haver muita controvérsia acerca da possibilidade de utilização de outras fontes para a interpretação das obrigações da OMC (como inclusive expressamente permitido pelo Artigo 3.2 do Entendimento). Apesar disso, atendo-se formalmente ao texto do ESC, não se verifica nem 
UM REGIME AUTOCONTIDO? APONTAMENTOS SOBRE O DIREITO APLICÁVEL AOS CONTENCIOSOS NO ÂMBITO DA OMC

ARno Dal RI JÚNIOR, MARIANA CLARA DE ANDRADE

expressa vedação, nem abertura à utilização de fontes de direito internacional geral dentro do âmbito da OMC. Assim sendo, infere-se que tal abertura (ou fechamento) será interpretada pelo MSC.

A OMC foi concebida no cenário do direito internacional geral, contando inclusive com os mesmos sujeitos que interagem também fora de seu âmbito. Ademais, o ESC não estabelece uma proibição à utilização de normas externas dentro do MSC, mesmo que se considerem os dispositivos analisados como limitações jurisdicionais. Por conseguinte, ainda que sua especialização e mesmo a competência restrita do seu mecanismo de solução de litígios limitem a sua dinâmica com o direito externo, este não pode ser ignorado, evitando-se a incoerência e a fragmentação e isolamento do direito internacional.

\section{REFERÊNCIAS}

BARTELS, Lorand. Jurisdiction and Applicable Law in the WTO. Cambridge: Cambridge University Press, 2014. Disponível em: <http://ssrn.com/abstract=2500684>. Acesso em: 09 fev. 2014.

. Applicable Law in WTO Dispute Settlement Proceedings. Journal Of World Trade Law, The Netherlands, v. 35, n. 3, p.499-519, mar. 2001.

CAMERON, James; GRAY, Kevin R.. Principles of International Law in the WTO Dispute Settlement Body. International and Comparative Law Quarterly,Cambridge, v. 50, n. 02, pp. 248-298, abril 2001.

CRAWFORD, James. Chance, Order, Change: The Course of International Law. The Hague: Brill, 2013.

DAL RI JÚNIOR, Arno. História do Direito Internacional: Comércio e Moeda, Cidadania e Nacionalidade. Florianópolis: Fundação Boiteux, 2004.

HOEKMAN, Bernard M.; MAVROIDIS, Petros C.. The World Trade Organization: law, economics and politics. New York: Routledge, 2007. (Global Institutions Series).

IRWIN, Douglas A.; C.MAVROIDIS, Petros; SYKES, Alan O.. The Genesis of the GATT. New York: Cambridge University Press, 2008.

KOSKENNIEMI, Martti. Outline of the Chairman of the ILC Study Group on Fragmentation of International law: The function and scope of the lex specialis rule and the question of 'selfcontained regimes'. 2004. Disponível em:

<http://legal.un.org/ilc/sessions/55/fragmentation_outline.pdf>. Acesso em: 28 jan. 2015. 
UM REGIME AUTOCONTIDO? APONTAMENTOS SOBRE O DIREITO APLICÁVEL AOS CONTENCIOSOS NO ÂMBITO DA OMC

ARNo DAL RI JÚNIOR, MARIANA CLARA DE ANDRADE

KOSKENNIEMI, Martti; LEINO, Päivi. Fragmentation of International Law? Postmodern Anxieties. Leiden Journal Of International Law, Leiden, v. 15, n. 3, p.553-579, nov. 2002. Disponível em: <http://repositoriocdpd.net:8080/bitstream/handle/123456789/588/Art_KoskenniemM_Fragmen tationInternationalLaw_2002.pdf?sequence=1>. Acesso em: 09 fev. 2015.

LINDROOS, Anja; MEHLING, Michael. Dispelling the Chimera of 'Self-Contained Regimes' International Law and the WTO. The European Journal Of International Law, Oxford, v. 16, n. 5, p.857-877, ago. 2006.

MARCEAU, Gabrielle Zoe. A call for coherence in international law: praises for the prohibition against "Clinical Isolation" in WTO dispute settlement. Journal of World Trade, Great Britain, v. 33, n. 5, p. 87-152, 1999.

MAVROIDIS, Petros C.; PALMETER, David. The WTO Legal System: Sources of Law. The American Journal of International Law, v. 92, n. 3, pp. 398-413, Jul. 1998.

MAVROIDIS, Petros C.. Remédios no Sistema Jurídico da OMC: Entre um Rochedo e um Lugar Difícil. Tradução de: Ciro Mioranza. In: RI JÚNIOR, Arno dal; OLIVEIRA, Odete Maria de (Org.). Direito Internacional Econômico em Expansão: Desafios e Dilemas. Ijuí: Unijuí, 2003. p. 229231.

PAUWELYN, Joost. The Role of Public International Law in the WTO: How Far Can We Go?. American Journal of International Law, v. 95, pp. 535-578, 2001.

PAUWELYN, Joost. Conflict of Norms in Public International Law: How WTO Law Relates to other Rules of International Law. New York: Cambridge University Press, 2003.

PULKOWSKI, Dirk; SIMMA, Bruno. Of Planets and the Universe: Self-contained Regimes in International Law. The European Journal Of International Law, Oxford, v. 17, n. 3, p.483-529, jun. 2006.

SAMPSON, Gary P.. The world trade organization and sustainable development. Hong Kong: United Nations University Press, 2005.

STOLL, Peter-tobias; SCHORKOPF, Frank. World Economic Order, World Trade Law. Leiden: Martinus Nijhoff, 2006. (Max Planck Commentaries on World Trade Law).

TREVES, Tullio. Fragmentation of International Law: The Judicial Perspective. Agenda Internacional, Peru, v. 27, n. 1, p.213-253, mar. 2009. Disponível em:

<http://revistas.pucp.edu.pe/index.php/agendainternacional/article/download/6728/6845>. Acesso em: 09 fev. 2015.

BOSSCHE, Peter van Den. The Law and Policy of the World Trade Organization: Text, Cases and Materials. New York: Cambridge University Press, 2005.

VANGRASSTEK, Craig. The History and Future of the World Trade Organization. Geneva: World Trade Organization, 2013.

Normas internacionais 
BRASIL. Ministério do Desenvolvimento, Indústria e Comércio Exterior (MDIC). Entendimento Relativo às Normas e Procedimentos sobre Solução de Controvérsias (ESC). Disponível em: <http://www.desenvolvimento.gov.br/arquivo/secex/omc/acordos/portugues/26anexo2.pdfhtt p://www.desenvolvimento.gov.br/arquivo/secex/omc/acordos/portugues/26anexo2.pdf>. Acesso em: 26 ago. 2014.

BRASIL. Convenção de Viena Sobre O Direito dos Tratados: DECRETO № 7.030, DE 14 DE DEZEMBRO DE 2009. Brasília, 2009. Disponível em:

<http://www.planalto.gov.br/ccivil_03/_Ato2007-2010/2009/Decreto/D7030.htm>. Acesso em 30.01.2015.

\section{Decisões do MSC/OMC}

WT/DS2/AB/R. United States - Standards for Reformulated and Conventional Gasoline. 1996. Disponível em: http://www.wto.org/english/tratop_e/dispu_e/cases_e/ds2_e.htm. Acesso em 20.01.2015.

WT/DS26/AB/R. European Communities - Measures Concerning Meat and Meat Products (Hormones). 1998. Disponível em:

http://www.wto.org/english/tratop_e/dispu_e/cases_e/ds26_e.htm. Acesso em 20.01.2015.

WT/DS58/AB/R. United States - Import Prohibition of Certain Shrimp and Shrimp Products. 1998. Disponível em: http://www.wto.org/english/tratop_e/dispu_e/cases_e/ds58_e.htm. Acesso em 20.01.2015.

WT/DS69/AB/R. European Communities - Measures Affecting Importation of Certain Poultry Products. 1998. Disponível em:

http://www.wto.org/english/tratop_e/dispu_e/cases_e/ds69_e.htm. Acesso em 20.01.2015.

WT/DS163/R. Korea - Measures Affecting Government Procurement. 2000. Disponível em: http://www.wto.org/english/tratop_e/dispu_e/cases_e/ds163_e.htm. Acesso em 20.01.2015. 